\title{
Arthroscopically Assisted Bone Grafting Reduces Union Time of Scaphoid Nonunions Compared to Percutaneous Screw Fixation Alone
}

\author{
Robert Gvozdenovic, MD ${ }^{1}$ (๑) Rasmus Wejnold Joergensen, MD ${ }^{1} \quad$ Stig Joerring, $M^{1}$ \\ Claus Hjort Jensen, $\mathrm{MD}^{1}$
}

${ }^{1}$ Gentofte/Herlev Hospital, University of Copenhagen, Department of Orthopedic Surgery, Hand Surgery Unit, Gentofte Hospital, Kildegårdsvej, Hellerup, Denmark

Address for correspondence Robert Gvozdenovic, MD, Department of Orthopedic Surgery, Hand Surgery Unit, Gentofte/Herlev Hospital, University of Copenhagen, Gentofte Hospital, Kildegårdsvej 28, opgang 17, stuen, 2900 Hellerup, Denmark

J Wrist Surg 2020;9:13-18

(e-mail: robert.g@dadlnet.dk; robert.gvozdenovic@regionh.dk).

\begin{abstract}
Purpose Minimally invasive techniques have been recommended in the treatment of painful but stable scaphoid nonunions. The purpose of this study was to determine if arthroscopically assisted bone grafting provided superior results in healing as compared to percutaneous screw fixation.

Materials and Methods One hundred sixty-four consecutive patients with scaphoid nonunions were retrospectively analyzed. One hundred forty-eight patients were treated with the open grafting techniques either with iliac or distal radius bone, leaving 16 patients treated with minimally invasive surgery. In the group treated percutaneously $(n=8)$, the time from injury to surgery was 2.5 months (range: $2-4$ months) and it was 27.3 months (range: $3-180$ months) in the arthroscopic group $(n=8)$. The mean age was 39 years (range: $20-66$ ) in the percutaneous group and 22 years (range: $16-32$ ) in the arthroscopic group. In all cases, the Mini Acutrak headless fully threaded compression screw was used. Healing was assessed clinically and radiographically at a minimum follow-up of 12 weeks, mean 7 months (range: 3-12 months). Data were calculated with two-tailed MannWhitney $U$ test based on $p$-value of $<0.05$ that was considered statistically significant.

Results We recorded no complications in any of the groups. Patients treated arthroscopically received cancellous bone grafting from the distal radius and all patients but one healed at a median of 7.8 weeks (range: $5-18$ weeks). Seven patients in the percutaneous group healed at a mean of 10.5 weeks (range: 7-24 weeks), thus leaving one patient from each group without achieving union. Mann-Whitney $U$ test showed the $U$ value of 11 , the critical value of $U$ to be $13(p<0.05)$, thus significantly

\section{Keywords}

- scaphoid nonunion

- minimally invasive

- arthroscopic

- percutaneous

- time to union

faster healing was observed in the arthroscopically treated group.

Conclusions Arthroscopically treated patients achieved faster healing despite shorter time to surgery in the percutaneous group. Local bone grafting is considered as the main reason for this outcome. Younger population in the arthroscopically treated group may have influenced the result.

Level of Evidence This is a Level III comparative study.
\end{abstract}

received

March 10, 2019

accepted after revision

May 18, 2019

published online

July 5, 2019
Copyright $@ 2020$ by Thieme Medical Publishers, Inc., 333 Seventh Avenue, New York, NY 10001, USA. Tel: +1(212) 760-0888.
DOI https://doi.org/

10.1055/s-0039-1693146. ISSN 2163-3916. 
The main goal in the treatment of a scaphoid nonunion is to achieve union of the scaphoid bone, thereby restoring the anatomy of the wrist and avoiding the occurrence of degenerative changes associated with the natural course of the scaphoid nonunion. ${ }^{1-3}$ The development of Scaphoid Nonunion Advance Collapse-Wrist, which is an irreversible, progressive chronic collapse of the carpal bones causing pain and diminishing wrist strength and function of the hand, should be avoided; thus, surgical efforts have been directed toward techniques that enable the treatment of the scaphoid nonunion. Since the 1960s, the gold standard in the treatment of scaphoid nonunion has been non-vascular grafting techniques, ${ }^{4}$ first without and later with $\mathrm{K}$-wires or screw fixation. Use of either the structural (corticocancellous) or the cancellous-only iliac bone graft (IBG) or bone from the distal part of the radius (DRG) has been advocated in a retrospective study of 68 patients that found no difference in the union rate between these two graft donor sites. $^{5}$ Union rates of 66 and $67 \%$ were noted with IBG (44 patients) and DRG (24 patients), respectively, although IBG patients experienced donor site pain at the iliac crest in $21 \%$ of the cases. Vascular bone grafting was impressive ${ }^{6-9}$; however, union rates varied from 27 to $100 \%$. Indeed, there was no difference in union rate, time to union, or functional result in a randomized trial of 80 patients treated with either vascular or nonvascular graft, ${ }^{10}$ and the graft failed to unite in three patients in the vascular graft group. Promising results have been obtained with minimally invasive treatments of scaphoid nonunions, regardless of the presence of cystic formations or small contact area. Because these treatments do not interrupt patient's blood supply and proprioception, faster union and functional recovery are expected.

The union rate and healing potential with percutaneous $^{11-15}$ and arthroscopically assisted ${ }^{16-20}$ techniques for the treatment of scaphoid nonunion have not been discussed at length. Indeed, comparative studies of different treatment options are rare in the literature. ${ }^{10,21}$ Therefore, the objective of this study was to determine whether healing achieved using arthroscopically assisted bone grafting was superior to that achieved using percutaneous screw fixation alone for the treatment of scaphoid delayed unions and nonunions.

\section{Materials and Methods}

This was a retrospective analysis of 164 consecutive patients who underwent treatment for delayed union or nonunion of the scaphoid bone at our institution between 2007 and 2017. The majority of patients $(n=143)$ were treated using open techniques and grafting, either with IBG or DRG bone grafting options. Among the remaining patients, 5 received vascular graft and 16 were treated using minimally invasive techniques. The Mini Acutrac, a headless, fully threaded compression screw system (Acumed; Hillsboro, Oregon) was used in all cases treated using minimally invasive techniques. For this comparative, evidence level III study, patients were divided in two groups: the group treated percutaneously with screw fixation only $(n=8)$ and the group treated with arthroscopically assisted bone grafting (DRG) from the ipsilateral radius bone $(n=8)$.
Table 1 Principal patient characteristics

\begin{tabular}{|l|l|l|}
\hline $\begin{array}{l}\text { Patients } \\
\text { characteristics }\end{array}$ & $\begin{array}{l}\text { Percutaneous } \\
\text { group }(\boldsymbol{n}=8)\end{array}$ & $\begin{array}{l}\text { Arthroscopically } \\
\text { assisted group } \\
(\boldsymbol{n}=8)\end{array}$ \\
\hline Gender M/F & $7 / 1$ & $7 / 1$ \\
\hline Age (y) & $39(20-66)$ & $22(16-32)$ \\
\hline $\begin{array}{l}\text { Time from injury } \\
\text { to treatment (mo) }\end{array}$ & $2.5(2-4)$ & $27.3(3-180)$ \\
\hline $\begin{array}{l}\text { Delayed union/ } \\
\text { nonunion }\end{array}$ & $8 / 0$ & $4 / 4$ \\
\hline $\begin{array}{l}\text { Number of active } \\
\text { smokers }\end{array}$ & 2 & 1 \\
\hline $\begin{array}{l}\text { Alcohol habits } \\
>14 \text { units/wk (M) } \\
>7 \text { units/wk (F) }\end{array}$ & 0 & 0 \\
\hline $\begin{array}{l}\text { Medication } \\
\text { including } \\
\text { steroids }\end{array}$ & 0 & \\
\hline
\end{tabular}

Note the difference in age, time to surgery, and the number of delayed/ nonunion cases between the groups.

Patient characteristics are shown in - Table 1. Only two patients in the percutaneous group exhibited nonunion at the proximal pole, whereas this nonunion was observed in four (50\%) patients treated arthroscopically (-Table 2 ). All patients but one was "missed fractures" and had not received a regular treatment where the treatment was initiated within the first few weeks after the injury. The only patient who received a proper treatment was conservatively treated with thumb/wrist immobilization for 8 weeks prior to the surgical treatment in the arthroscopic group.

All patients were preoperatively investigated using radiographic series and computed tomography (CT) images of the wrist. The exclusion criteria for the minimally invasive treatment included humpback deformity of the scaphoid bone where intrascaphoid angle (ISA) on the CT long-axis series was $>45^{\circ}$, together with the presence of bony cysts

Table 2 Difference between the groups regarding the location of the nonunion, the presence of mild humpback deformity, bony cysts, and differences in the surgical approach

\begin{tabular}{|l|l|l|}
\hline Parameter & $\begin{array}{l}\text { Percutaneous } \\
\text { group }(\boldsymbol{n}=\mathbf{8})\end{array}$ & $\begin{array}{l}\text { Arthroscopically } \\
\text { assisted group } \\
(\boldsymbol{n}=\mathbf{8})\end{array}$ \\
\hline $\begin{array}{l}\text { Location of the } \\
\text { nonunion }\end{array}$ & $\begin{array}{l}\text { Proximal }=2 \\
\text { Waist }=5 \\
\text { Distal }=1\end{array}$ & $\begin{array}{l}\text { Proximal }=4 \\
\text { Waist }=4 \\
\text { Distal }=0\end{array}$ \\
\hline $\begin{array}{l}\text { Mild humpback } \\
\text { deformity } \\
\left.\text { (ISA angle }<45^{\circ}\right)\end{array}$ & $n=0$ & $n=2$ \\
\hline $\begin{array}{l}\text { Presentation of the } \\
\text { bony cysts }<10 \mathrm{~mm}\end{array}$ & $>5 \mathrm{~mm}=2$ & $\begin{array}{l}<5 \mathrm{~mm}=4 \\
>5 \mathrm{~mm}=3\end{array}$ \\
\hline $\begin{array}{l}\text { Volar/dorsal } \\
\text { approach }\end{array}$ & $6 / 2$ & $0 / 8$ \\
\hline
\end{tabular}

Abbreviation: ISA, intrascaphoid angle. 
$>10 \mathrm{~mm}$. Two patients in the arthroscopic group were registered with mild humpback deformity $\left(<45^{\circ}\right)$. Four patients in the percutaneous group and seven in the arthroscopic group had cysts. All patients with the nonunion presentation in the proximal pole underwent gadoliniumenhanced magnetic resonance imaging (MRI) preoperatively. If the MRI findings showed signs of avascular necrosis (AVN) of the proximal pole of the scaphoid, patients were excluded from minimally invasive treatment and were treated either using a vascular graft or with a salvage procedure using an adaptive proximal scaphoid implant pyrocarbon spacer. All patients were operated at a day-surgery center under the lateral infraclavicular or axillary-block regional anesthesia.

Healing was assessed clinically and radiographically at a minimum follow-up period of 12 weeks, a mean of 7 months (range: 3-12 months). The postoperative regimen was identical in both groups and comprised immobilization for 6 weeks (first in the thumb/wrist splint for 2 weeks, followed by removable orthosis for another 4 weeks), allowing the hand therapist to initiate the non-weight-bearing exercises. Patients were assessed clinically for scaphoid tenderness and pain on movement and using scaphoid series radiographs on the 6th postoperative week. The wrist was mobilized without restriction if the union was established. If healing could not be confirmed, the removable bellow-elbow splint was worn for intervals of 2 to 4 weeks until union was established. CT was performed in cases with findings of painful wrist on clinical examination and incomplete or lack of union on scaphoid radiographic examination (-Fig. 1) (-Table 3). Patients were deemed functionally cured and were fully mobilized only when the long-axis CT reconstruction series showed healing in $>50 \%$ of bridging trabeculae in both coronal and sagittal planes ${ }^{22}$; however, they were recommended to avoid contact sports or excessive use of force until next follow-up visit. Statistical analysis was performed using two-tailed Mann-Whitney $U$ test. $p<0.05$ was considered statistically significant. All the patients provided written informed consent for the use of their medical data for the purpose of this study, according to the ethical and patient-safety standards in Denmark.
Table 3 Assessment of the postoperative healing reflecting daily practice

\begin{tabular}{|l|l|l|}
\hline $\begin{array}{l}\text { Assessment of the } \\
\text { postoperative } \\
\text { healing }\end{array}$ & $\begin{array}{l}\text { Percutaneous } \\
\text { group } \\
(\boldsymbol{n}=\mathbf{8})\end{array}$ & $\begin{array}{l}\text { Arthroscopically } \\
\text { assisted group } \\
(\boldsymbol{n}=\mathbf{8})\end{array}$ \\
\hline $\begin{array}{l}\text { Clinical examination }+ \\
\text { scaphoid radiographs }\end{array}$ & 7 & $\mathbf{4}$ \\
\hline $\begin{array}{l}\text { Supplementary } \\
\text { CT scan }\end{array}$ & 1 & 4 \\
\hline
\end{tabular}

Abbreviation: $\mathrm{CT}$, computed tomography.

\section{Results}

There were no perioperative complications in any patient. Minimally invasive techniques applied in this study showed equivalent fusion rates. One patient in each group did not show signs of healing, neither on radiographs nor on CT images; both the patients declined further treatment due to the lack of symptoms. In the percutaneous group (seven patients, 87.5\%), the mean healing duration was 10.5 weeks (range: 7-24 weeks). In the arthroscopic group, the mean healing duration in all patients except one (87.5\%) was 7.8 weeks (range: $5-18$ weeks); healing was significantly faster than in the percutaneous group (Mann-Whitney $U$ test $\mathrm{u}$ value $=11$, the critical value of $U=13)(p<0.05)$. In the arthroscopic group, union was achieved within the first 8 weeks in six of seven patients, of those six patients, union was achieved within the 6th postoperative week in five patients (-Table 4 ). Operation time was significantly higher in the arthroscopic group (average 140 min; range: $96-197 \mathrm{~min}$ ) than in the percutaneous group (average $36 \mathrm{~min}$; range: $10-53 \mathrm{~min})(p<0.05)$.

\section{Discussion}

Arthroscopically assisted treatment of scaphoid nonunion has garnered considerable interest among hand surgeons since 2006, when the original technique was introduced. ${ }^{23}$ Slade and Gillon ${ }^{24}$ have retrospectively investigated 108 scaphoid nonunion patients for a mean of 20 months from
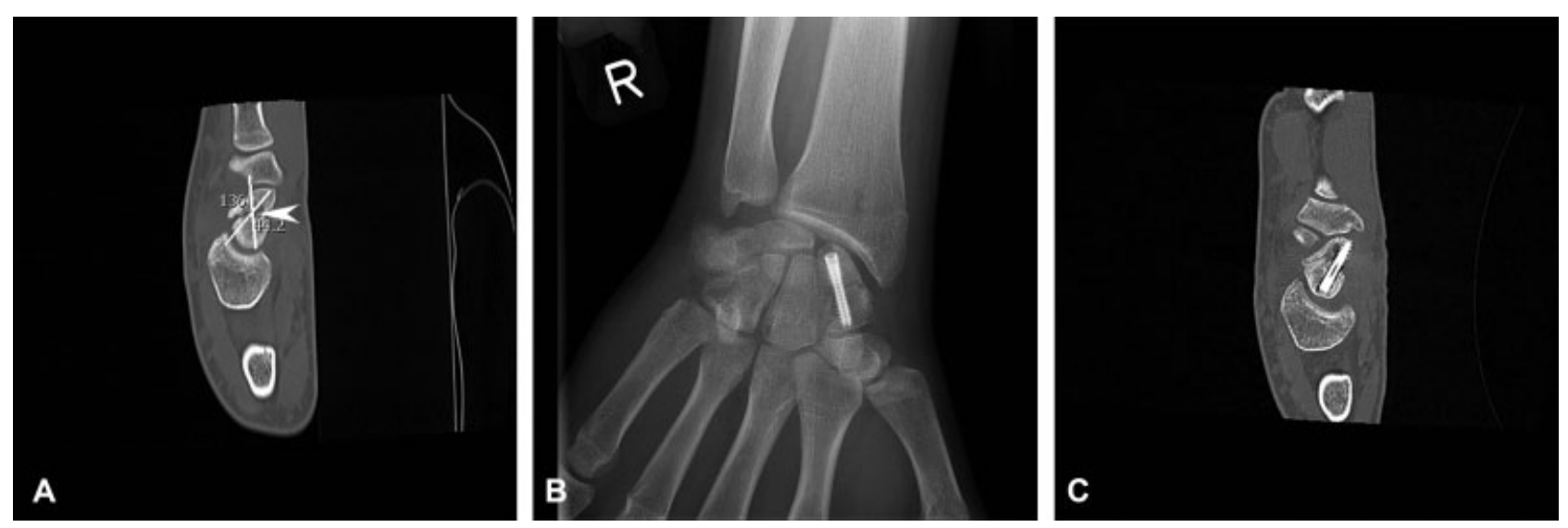

Fig. 1 Preoperative computed tomography (CT) showing a mild humpback deformity and an intrascaphoid angle of $44^{\circ}$ (white lines) and the occurrence of the bony cyst $>5 \mathrm{~mm}$ (white arrow; A). Radiographs taken 7 weeks postoperatively showing uncertain signs of healing; the patients had persistent pain (B). CT image obtained at 10 weeks postoperatively shows union (C). 
Table 4 Outcomes showing the number of patients with healing/failures, time to union, and the dispersion of the union within weeks in percutaneous and arthroscopically assisted groups

\begin{tabular}{|l|l|l|l|}
\hline Parameter & $\begin{array}{l}\text { Percutaneous } \\
\text { group }(\boldsymbol{n}=\mathbf{8})\end{array}$ & $\begin{array}{l}\text { Arthroscopically assisted } \\
\text { group }(\boldsymbol{n}=\mathbf{8})\end{array}$ & $\begin{array}{l}\text { Statistical significance } \\
\text { (Mann-Whitney U test) }\end{array}$ \\
\hline Number of unions/failures & $n=7 / 1$ & $n=7 / 1$ & \\
\hline Time to union (weeks) & $\begin{array}{l}10.5 \text { (mean) } \\
\text { (range: } 7-24)\end{array}$ & $\begin{array}{l}7.8(\text { mean) } \\
\text { (range: } 5-18)\end{array}$ & $p<0.05$ \\
\hline Time to union within the weeks & $<6$ weeks $=(0)$ & $<6$ weeks $=(5)$ \\
(number of patients) & $>6<$ weeks $=(4)$ & $>8$ weeks $=(1)$ & \\
& $>8$ weeks $=(3)$ & weeks $=(1)$ & \\
\hline
\end{tabular}

injury to surgery; union was observed in $76 \%$ of them within 6 to 8 weeks of the surgery. However, the total mean union time was 22 weeks, with 10 patients requiring regrafting; among these 10 patients, there was failure to unite in four patients after 9 months. Wong and $\mathrm{Ho}^{17}$ have reported an overall union rate of $90.7 \%$ (mean 12 weeks) after the treatment of 43 scaphoid nonunions; among them, six cases had delayed union for $<6$ months. In this study, proximal pole nonunion resulted in a union rate of $78 \%$. Kang et al ${ }^{19}$ have reported healing in 32 out of 33 arthroscopically treated patients. Patients with AVN of the proximal pole and humpback deformity, where ISA on CT series was $>45^{\circ}$, were excluded from this treatment. Other studies of arthroscopically assisted techniques have reported good or excellent union rates and functional results. ${ }^{16,18,20}$ Mahmoud and Koptan $^{11}$ have reported achieving $100 \%$ union rate in 27 patients at a mean of 12 weeks using a percutaneous technique without bone grafting where patients with humpback deformity did not undergo the treatment. The authors found a correlation between the time from injury to surgery and healing time. When time to surgery was $<1$ year, patients healed within a mean duration of 9 weeks, whereas when time to surgery was $>1$ year, patients needed a mean duration of 12 weeks to achieve union. Moreover, it was observed that if nonunion gap was $<5 \mathrm{~mm}$ in diameter, the mean time to union was 12 weeks (mean); however, if the cystic gap was $>5 \mathrm{~mm}$, the mean time to union was 14 weeks. We could not find the above-mentioned correlation in any of the groups in our study. Vanhees et al ${ }^{15}$ have reported achieving $94 \%$ union in a case series of 16 patients treated using a percutaneous technique where the mean time to union was 4 months ( 17 weeks). Recently, favorable results and high union rates with percutaneous techniques have been reported in multiple studies, ${ }^{12-14}$ although the exact time to union has not been reported in all the studies.

The major risk factors involved in the failure of treatment for this condition are the duration between the injury and the surgical treatment, as well as the localization of the nonunion in the proximal pole ${ }^{25}$ (-Fig. 2). It is plausible that in the percutaneous group in our study, both of the abovementioned factors might have been favorable, which allowed a faster healing. Conversely, the significantly younger age of the patients in the arthroscopic group may have provided them with an advantage in terms of faster union. Other features such as smoking habits, alcohol consumption, and use of heavy medications, including steroids, did not differ between our study groups.

Operation time was significantly higher in the arthroscopic group than in the percutaneous group probably due to the learning curve of this technically more advanced method. Shorter time to union indicates faster return to work and daily routine in this active, young, working patient population,
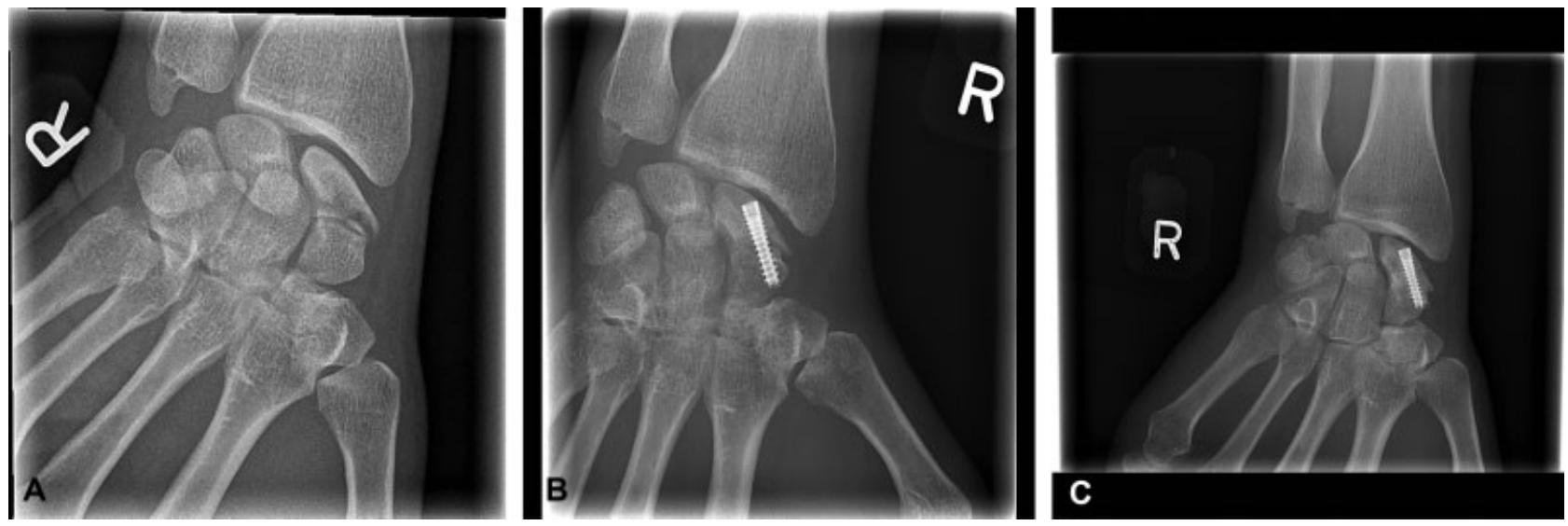

Fig. 2 A 32-year-old man had a 15-year-old nonunion with moderate symptoms until a recent fall from a bike, resulting in comminuted fracture of the waist of the same scaphoid (A). He was treated using local grafting and arthroscopically assisted technique; union was achieved both at the nonunion and fracture sites at 6 weeks (B). Status at 1-year follow-up (C). 
justifying the longer operation time of the arthroscopic treatment. However, the operating time for the arthroscopic technique has diminished substantially and is currently at the level of the usual tourniquet time (90-120 min). A recent comparative study of open and arthroscopic bone grafting, where IBG was used in both groups, found significant differences in operating time in favor of the open technique, without considering the time to union, whereas union rates or functional results did not differ between the groups. Although there were no differences in clinical outcomes between the two techniques, open grafting restored better carpal alignment than the arthroscopic technique. ${ }^{21}$

Our study is not without limitations. This was a retrospective study that lacked clear inclusion criteria for the treatment groups. Patients included in the percutaneous group were presumed to heal faster if they were operated upon instead of initiating a long conservative treatment for them. Arthroscopically treated patients were estimated to be stable enough, not requiring a structural graft to correct the humpback deformity, on the basis of preoperative CT imaging findings. Furthermore, the predictive value of CT measurements (i.e., dorsal cortical angle, ISA, height-to-length ratio, presence of bony cysts) for determining healing rate and time in the treatment of the scaphoid nonunion remains unknown and warrants further investigation.

Another limitation of our study is that postoperative CT images were not obtained for all cases, but preferably for cases with persistent pain and/or cases where radiographic findings regarding the state of union were concerning. Modern CT scan techniques with less radiation exposure and metal artifact reduction options were not available at our institution at study initiation. Inclusion of both radiographs and CT images in defining union reflected our recent daily practice. In fact, none of the patients who were initially proclaimed to have achieved union and were fully mobilized reversed to nonunion during the follow-up visits. Despite the relatively low number of cases in each group in our study, the results were eligible for statistical analysis using Mann-Whitney U test.

As the usual follow-up period is 2 to 4 weeks, the clinical significance of a difference of 2.7 weeks (18.9 days), despite achieving statistical significance, is likely to have an impact and is a valid point for discussion. This emphasizes the need for frequent clinical and imaging assessment of the patients in order to avoid unnecessary immobilization and duration of disability. Furthermore, both the groups underwent similar clinical and imaging assessments. All patients, but one, in the percutaneous group underwent surgery performed by the same hand surgeon and were followed up postoperatively in a similar fashion.

\section{Conclusions}

In this study, both percutaneously treated group with screw fixation of delayed unions and the group treated with arthroscopically assisted bone grafting (DRG) from the ipsilateral radius bone of scaphoid nonunion achieved similarly high union rates. Arthroscopically treated patients achieved significantly faster healing, despite a significantly longer time from injury to surgery and a higher presence of proximal pole nonunion and bony cysts. This was attributed to the debridement of the nonunion site and bone grafting under direct arthroscopic view. The results from this study showed that healing achieved using arthroscopically assisted bone grafting was superior to that achieved using percutaneous screw fixation alone for the treatment of scaphoid delayed unions and nonunions, but a larger, preferably randomized trial for different treatment methods is warranted.

Conflict of Interest

None declared.

\section{References}

1 Ruby LK, Stinson J, Belsky MR. The natural history of scaphoid non-union. A review of fifty-five cases. J Bone Joint Surg Am 1985; 67(03):428-432

2 Lindström G, Nyström A. Incidence of post-traumatic arthrosis after primary healing of scaphoid fractures: a clinical and radiological study. J Hand Surg [Br] 1990;15(01):11-13

3 Inoue G, Sakuma M. The natural history of scaphoid non-union. Radiographical and clinical analysis in 102 cases. Arch Orthop Trauma Surg 1996;115(01):1-4

4 Russe O. Fracture of the carpal navicular. Diagnosis, non-operative treatment, and operative treatment. J Bone Joint Surg Am 1960;42-A:759-768

5 Tambe AD, Cutler L, Murali SR, Trail IA, Stanley JK. In scaphoid non-union, does the source of graft affect outcome? Iliac crest versus distal end of radius bone graft. J Hand Surg [Br] 2006;31 (01):47-51

6 Zaidemberg C, Siebert JW, Angrigiani C. A new vascularized bone graft for scaphoid nonunion.J Hand Surg Am 1991;16(03):474-478

7 Steinmann SP, Bishop AT, Berger RA. Use of the 1,2 intercompartmental supraretinacular artery as a vascularized pedicle bone graft for difficult scaphoid nonunion. J Hand Surg Am 2002;27 (03):391-401

8 Straw RG, Davis TR, Dias JJ. Scaphoid nonunion: treatment with a pedicled vascularized bone graft based on the 1,2 intercompartmental supraretinacular branch of the radial artery. J Hand Surg [Br] 2002;27(05):413

9 Chang MA, Bishop AT, Moran SL, Shin AY. The outcomes and complications of 1,2-intercompartmental supraretinacular artery pedicled vascularized bone grafting of scaphoid nonunions. J Hand Surg Am 2006;31(03):387-396

10 Braga-Silva J, Peruchi FM, Moschen GM, Gehlen D, Padoin AV. A comparison of the use of distal radius vascularised bone graft and non-vascularised iliac crest bone graft in the treatment of non-union of scaphoid fractures. J Hand Surg Eur Vol 2008;33(05):636-640

11 Mahmoud M, Koptan W. Percutaneous screw fixation without bone grafting for established scaphoid nonunion with substantial bone loss. J Bone Joint Surg Br 2011;93(07):932-936

12 Saint-Cyr M, Oni G, Wong C, Sen MK, Lajoie AS, Gupta A. Dorsal percutaneous cannulated screw fixation for delayed union and nonunion of the scaphoid. Plast Reconstr Surg 2011;128(02):467-473

13 Altay T, Gunal I, Kayali C, Sener M. Dorsal percutaneous screw fixation of delayed or nonunion of scaphoid fractures: decision making with MRI. Int Orthop 2014;38(05):1007-1010

14 Ohta S, Ikeguchi R, Noguchi T, et al. Percutaneous fixation for scaphoid nonunion with bone grafting through the distal insertion hole of a fully threaded headless screw.J Hand Surg Asian Pac Vol 2016;21(03):357-363

15 Vanhees M, van Riet RRP, van Haver A, Kebrle R, Meermans G, Verstreken F. Percutaneous, transtrapezial fixation without bone graft leads to consolidation in selected cases of delayed union of the scaphoid waist. J Wrist Surg 2017;6(03):183-187 
18 Arthroscopic versus Percutaneous Screw Fixation Reduces Union Time of Scaphoid Nonunions Gvozdenovic et al.

16 Chu PJ, Shih JT. Arthroscopically assisted use of injectable bone graft substitutes for management of scaphoid nonunions. Arthroscopy $2011 ; 27(01): 31-37$

17 Wong WY, Ho PC. Minimal invasive management of scaphoid fractures: from fresh to nonunion. Hand Clin 2011;27(03):291-307

$18 \mathrm{Kim}$ JP, Seo JB, Yoo JY, Lee JY. Arthroscopic management of chronic unstable scaphoid nonunions: effects on restoration of carpal alignment and recovery of wrist function. Arthroscopy 2015;31 (03):460-469

19 Kang HJ, Chun YM, Koh IH, Park JH, Choi YR. Is arthroscopic bone graft and fixation for scaphoid nonunions effective? Clin Orthop Relat Res 2016;474(01):204-212

20 Cognet JM, Louis P, Martinache X, Schernberg F. Arthroscopic grafting of scaphoid nonunion - surgical technique and preliminary findings from 23 cases. Hand Surg Rehabil 2017;36(01): $17-23$
21 Oh WT, Kang HJ, Chun YM, Koh IH, Lee YJ, Choi YR. Retrospective comparative outcomes analysis of arthroscopic versus open bone graft and fixation for unstable scaphoid nonunions. Arthroscopy 2018;34(10):2810-2818

22 Singh HP, Forward D, Davis TR, Dawson JS, Oni JA, Downing ND. Partial union of acute scaphoid fractures. J Hand Surg [Br] 2005; 30(05):440-445

23 Slade JF III, Dodds SD. Minimally invasive management of scaphoid nonunions. Clin Orthop Relat Res 2006;445(445):108-119

24 Slade JF III, Gillon T. Retrospective review of 234 scaphoid fractures and nonunions treated with arthroscopy for union and complications. Scand J Surg 2008;97(04):280-289

25 Ramamurthy C, Cutler L, Nuttall D, Simison AJ, Trail IA, Stanley JK. The factors affecting outcome after non-vascular bone grafting and internal fixation for nonunion of the scaphoid. J Bone Joint Surg $\mathrm{Br}$ 2007;89(05):627-632 